\title{
Investigation of Corrosion Resistance of Alloys with Potential Application in Supercritical Water-cooled Nuclear Reactors
}

\author{
Ákos Horváth ${ }^{1 *}$, Attila R. Imre',2, György Jákli \\ 1 Institute for Atomic Energy Research, MTA Centre for Energy Research, Hungarian Academy of Sciences, \\ H-1525 Budapest, POB 49, Hungary \\ 2 Department of Energy Engineering, Faculty of Mechanical Engineering, Budapest University of Technology and Economics, \\ H-1111 Budapest, Műegyetem rkp. 3., Hungary \\ *Corresponding author, e-mail: akos.horvath@energia.mta.hu
}

Received: 29 July 2018, Accepted: 08 January 2019, Published online: 25 February 2019

\begin{abstract}
The Supercritical Water Cooled Reactor (SCWR) is one of the Generation IV reactor types, which has improved safety and economics, compared to the present fleet of pressurized water reactors. For nuclear applications, most of the traditional materials used for power plants are not applicable, therefore new types of materials have to be developed. For this purpose corrosion tests were designed and performed in a supercritical pressure autoclave in order to get data for the design of an in-pile high temperature and high-pressure corrosion loop. Here, we are presenting some results, related to corrosion resistance of some potential structural and fuel cladding materials.
\end{abstract}

Keywords

high pressure, steel corrosion, supercritical water

\section{Introduction}

The Supercritical Water Cooled Reactor (SCWR) is one of the Generation IV reactor types, selected by Generation IV International Forum (GIF) for its improved safety and economics. The improvement is due to high thermal efficiency and plant simplification supported by the unchanged phase of the coolant in the reactor [1]. Although there are some applications for supercritical water (water above $374{ }^{\circ} \mathrm{C}$ and $22.1 \mathrm{MPa}$ ) in traditional (fossil-fuel) power plants, but this "material" has never been used commercial nuclear power applications, although some high-temperature $\left(>500^{\circ} \mathrm{C}\right)$ reactors were built for demonstration purpose in the 1950s and 1960s. Therefore, numerous questions regarding potential material problems emerged, which must be considered. In recent years extensive materials development has taken place within the fossil power generation programs. However this development work was mainly focused on the high temperatures mechanical properties; the oxidation and corrosion aspects have not been investigated adequately [2].

At present, no single candidate alloy has been identified as the potentially best alloy for use as either cladding or structural materials in SCWRs. Most of the research projects for the cladding and structural materials in SCWRs focus on acquiring data on various fields, including corrosion, radiolysis, water chemistry, dimensional and micro-structural stability, strength and creep resistance, combined effects of radiation induced and corrosion damages $[3,4]$.

Corrosion in particular has been identified as a critical problem because the very high temperature and the oxidative nature of supercritical water increase the corrosion rate. For fuel cladding material, the high chromium content $(\mathrm{Cr}>8 \%)$ ferritic steel and nickel base alloys seem to be resistant to the harsh environment. Not only corrosion resistance but neutron physics aspects should be considered during the selection of the cladding for reactor application; unfortunately both candidate types have significantly larger neutron adsorption than Zirconium base alloys. The increased neutron adsorption would require the use of thinner cladding walls (to be transparent for the fission neutrons), while to keep the mechanical stability of the reactor even on the high pressure of supercritical water (almost twice of the pressure used in traditional pressurized water reactors), thickness should be properly high. 
The design work of the SCWR needs material performance data in supercritical water either in or out-of-pile. In-pile loops circulating water at supercritical (SC) pressure are necessary to test components under the combined effect of corrosion and neutron radiation. Water loops built for supporting the research needs of the present fleet of BWRs and PWRs are very similar to SC loops. The main differences compared to a PWR loop are that SC loop operates at higher temperature and pressure, and with simplified water chemistry. For the safe operation of a SC loop, high temperature creep resistance is an important parameter.

In this paper, results obtained in various corrosion tests on selected supercritical water loop component materials are presented. Additionally, some material properties data for the design of an in-pile loop are reviewed.

\section{The miscibility of corrosion products}

The temperature range of normal working conditions for SCWR differs significantly from previous reactor types, like BWR (Boiling Water Reactor) or PWR (Pressurized Water Reactor) [5], as it can be seen in Fig. 1. Characteristic values for various types are marked; their numerical values are given in the figure legend. Here we have to mention, that in nuclear technology, the use of Celsius and bar are also widely accepted, therefore in several occasion, we are giving temperature and pressure values also in these units.

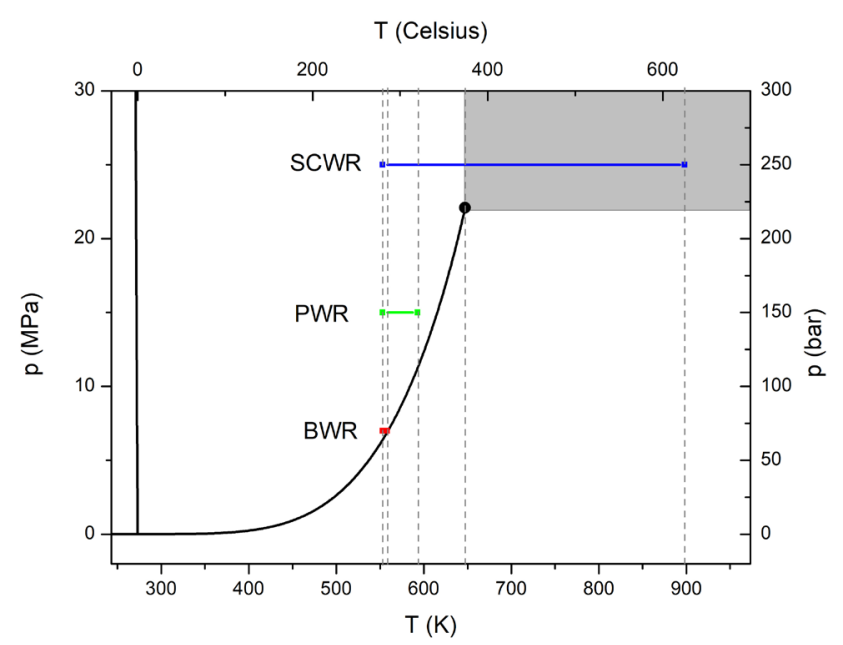

Fig. 1 Typical ranges for normal working conditions of Boiling Water Reactors (BWR; $p=7 \mathrm{MPa}, T=280-285^{\circ} \mathrm{C}$ ), Pressurized Water Reactors (PWR; $p=15 \mathrm{MPa}, T=280-320^{\circ} \mathrm{C}$ ) and Supercritical Water Cooled Reactors (SCWR; $p=25 \mathrm{MPa}, T=280-625^{\circ} \mathrm{C}$ ). Important temperature values are marked by grey dashed lines. The phase diagram of water (vapor pressure curve, melting line and saturation curve) are shown by black lines, critical point is marked by a black dot and the supercritical region - according to the traditional definition is marked by a grey region.
There are several important properties, in which supercritical water differs not only quantitatively but sometimes even qualitatively from the pressurized and hot but still subcritical one. Several properties - like isotherm compressibility, isobaric specific heat, etc. - has an extremum in the supercritical region, while they are monotonous and slowly changing functions of the temperature in the subcritical one. In the immediate vicinity of the critical point, these extrema can be very pronounced and they are still remarkable at $25 \mathrm{MPa}$. One can mark the location of these anomalies by lines connecting these extrema; they are often referred as Widom-lines [6, 7]. The location of these extrema has strong effect on the applicability of well-established thermohydraulic codes in the supercritical region [8].

One of the properties relevant in this case of the change of solubility of corrosion products in the supercritical region [9-11]. With some simplification, one can say that while the subcritical water is good solvent for inorganic and bad solvent for organic materials, it turns into the opposite in the SC region, it could dissolve several organic materials but could not dissolve or hardly dissolve some inorganic ones. While in the nuclear industry usually one does not have to worry about organic materials, inorganic ones - especially corrosion products - cannot be excluded. Although the miscibility of these inorganic materials is bad, i.e. their concentration cannot be high, they can still reach several hundreds of ppm. Even this small amount can shift the aforementioned extrema a little bit. This shift can cause measurable differences for between the expected and real quantities at a given temperature [11]. Since the miscibility behavior of various oxides in the supercritical region is not well-known and additionally we proper equation of state of these solutions do not exist, in most cases, - at least concerning thermal and flow-related problems - salty water can be used as a model.

According to our results, there are two distinct fields, where the presence of the inorganic solute can cause problems. First, some precipitation can be assumed in the high-temperature region of the supercritical loop. Although the concentrations are very low, assuming the length of a campaign in nuclear reactors, significant amount of oxides and hydroxides can precipitate. To make the problem more serious, the high temperature zone where the precipitation might happen is in the core of the reactor, where this material (probably magnetite, less likely hematite and other oxides), precipitated on the wall can cause heat transfer and flow problems too [12]. 
Second, that even small concentration can shift location (in pressure-temperature space) of the anomalous property-maxima mentioned before. It has been shown, that even a few ppm of inorganic material can cause 1-2 K shifts and approx. $20 \%$ decrease of the peaks. In case of stationer flow (i.e. with constant temperature profile) this can cause dislocation for some phenomena connected to the pseudospinodal peak. For example it can be expected that the local overheating of the wall caused by the deteriorated heat transfer will shift into different location. Also, the shift of compressibility peak might cause some turbulence in the flow [11].

\section{Materials for corrosion tests}

The currently envisioned SCWR plant design will utilize a direct power generation cycle. High pressure (25.0 MPa) coolant enters the vessel at $280{ }^{\circ} \mathrm{C}$. The coolant is heated to about $500{ }^{\circ} \mathrm{C}$ - or even at higher temperatures in various models - and delivered to a power conversion cycle, which is similar to that used in supercritical fossil-fired plants: high- intermediate- and low-pressure turbines are employed with two reheaters. The most significant factors in changing the materials needs in going from the current pressurized- and boiling-water reactor designs to the SCWR are those associated with the increase in outlet coolant temperature from 300 to $500{ }^{\circ} \mathrm{C}$. Zirconium alloys, which are widely used for fuel cladding material, won't be selected because of their poor corrosion resistance in steam above $300{ }^{\circ} \mathrm{C}$ [13]. Instead, high chromium steels and nickel base alloys are the most promising candidates for cladding and structural materials in supercritical water [14].

The materials selected for oxidation tests are candidates for structural materials, namely they are the candidates for materials of the heated test section wall. The official name / sign and a short description of these materials can be seen in Table 1 .

Table 1 Candidates for structural materials

\begin{tabular}{|c|c|}
\hline Name or sign & Description \\
\hline $15 \mathrm{H} 2 \mathrm{MFA}$ & $\begin{array}{c}\text { Cr-Mo-V steel, with good high temperature } \\
\text { creep properties. }\end{array}$ \\
\hline Eurofer97 & $\begin{array}{l}\text { European reference "reduced activation" } \\
\text { steel, designed for fusion devices. }\end{array}$ \\
\hline $\begin{array}{l}\text { AISI } 316 \text { type } \\
(\text { EN } 1.4401)\end{array}$ & $\begin{array}{l}\text { Conventional austenitic stainless steel for } \\
\text { comparison, with high chromium content, } \\
\text { but less creep resistance. }\end{array}$ \\
\hline Ti grade 2 alloy & Good corrosion and creep resistance alloy. \\
\hline
\end{tabular}

It should be mentioned here, that the UJV Institute in Rez built a supercritical water loop for its research reactor LVR15 , within the frame of the HPLWR Phase 2 project, a project related to design a European version of SCWR [15]. The structural material chosen for this loop is a Russian type stainless steel, very slightly different from AISI 316 type.

\section{The corrosion tests}

The oxidation tests were executed in the in-house made autoclave at $500{ }^{\circ} \mathrm{C}$ and at $25 \mathrm{MPa}$ pressure. The material of the pipes and fittings of the autoclave loop is made of AISI 316 type (also known as EN 1.4401) stainless steel, and the material of the heated test section was AISI 304 type (also known as EN 1.4301) stainless steel, a representative sample can be seen in Fig. 2 .

The total volume of the autoclave is about $100 \mathrm{~cm}^{3}$. High pressure was generated by an air driven hydraulic pump and controlled with a backpressure valve. The inner volume of the device was evacuated with a vacuum pump, and then it was filled up with degassed double-distilled water to minimize oxygen content.

The samples were ring shaped with an outer diameter of $9 \mathrm{~mm}$ and inner diameter of $5 \mathrm{~mm}$. The surfaces of the samples were about $1.03 \mathrm{~cm}^{2}$. The samples were electrically isolated from each other and the autoclave wall by ceramic washers. A typical sample can be seen in Fig. 3.

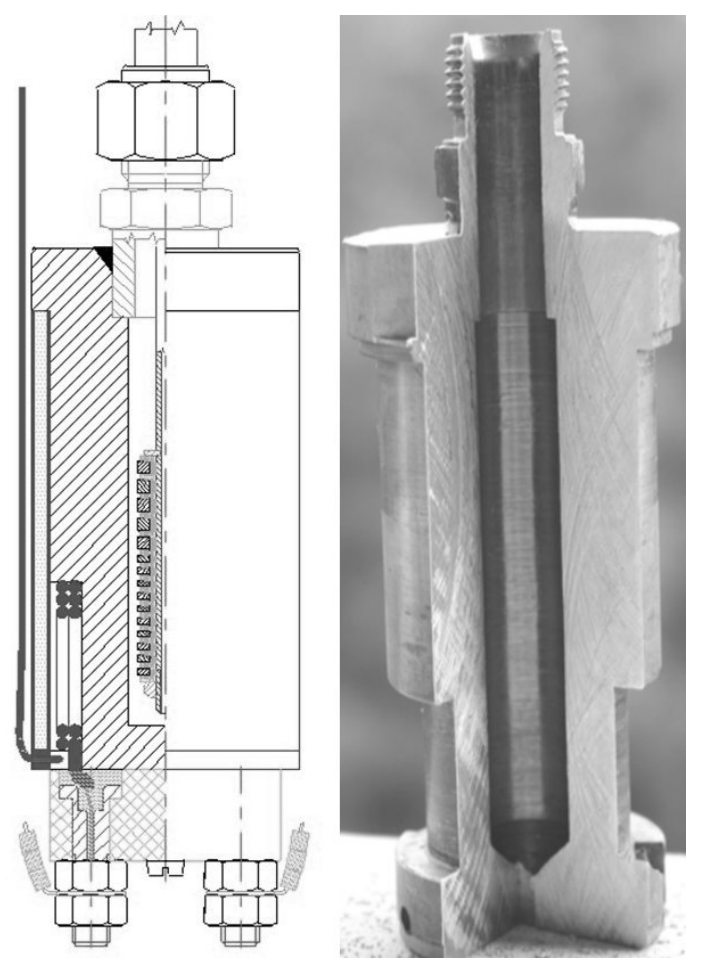

Fig. 2 Heated section of the Supercritical loop used for corrosion testing. 


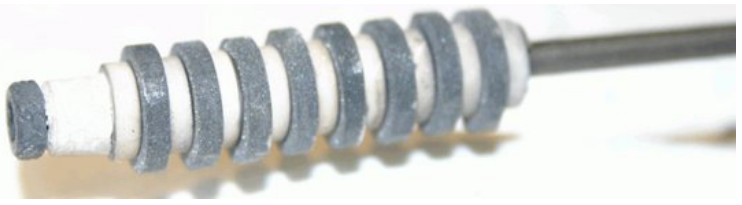

Fig. 3 Ring shaped samples, isolated by ceramic rings.

Samples were prepared by surface finish with \#600 paper, and then rinsed in ethanol.

Two separate long-term tests were executed for 1848 and 1632 hours (77 and 68 days respectively). 4-4 samples of each material were put in the autoclave and taken out every three weeks for the first and in every second week in the second tests for ex situ examination.

The first test was run with Eurofer97 and 15H2MFA materials, and AISI316 and Titanium alloys were loaded in the second. Weight gains of the samples were measured, and the cross section of them was analyzed optically by microscope. The weight gains were about 1-5 $\mathrm{mg}$ (in the first series, using Eurofer and 15H2MFA) and 0.1-0.5 mg (in the second test, using AISI316 and Ti alloy).

The results in terms of oxide layer thickness versus time are shown in Fig. 4. The oxide thickness was measured on the metallography images. The average was calculated from minimum 9 values for every sample.

The worse scored material is the 15H2MFA, which has good high temperature creep resistance, however it's corrosion resistance is very weak. Eurofer97 exhibited parabolic oxide growth kinetics within the test period. Both metals resulted in more than $10 \mathrm{~mm}$ oxide layer, which is not critical for a thick-wall device, however the falling "rust" particles as well as the dissolved oxides could contaminate the coolant.

In the second test the other two materials, AISI316 and Ti-grade 2 resulted in considerably smaller oxide thickness. The measured oxide thickness on AISI316 after 1000 hours is higher than those measured for shorter or longer time; the exact reason of this phenomenon is still unknown. The thickness in that case is the average of 15 values measured at different positions on the sample surface. Higher oxidation rate was observed at possible defect sites on the surface, which could increase the average thickness.

Titanium grade-2 alloy was also selected for the corrosion tests, as it exhibits good corrosion resistance and fast radioactive decay after activation. This alloy produced thin oxide layer similar to AISI316, resulted in a nearly linear kinetics and relatively small scatter in the thickness data. However with somewhat better mechanical

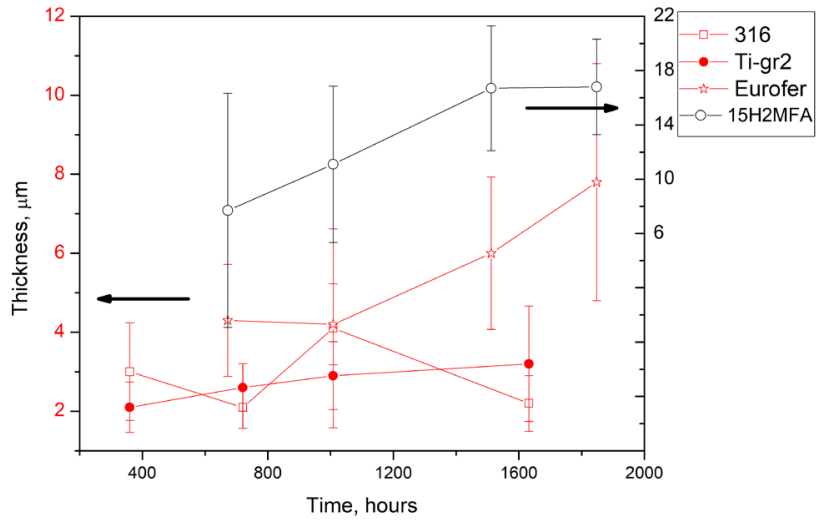

Fig. 4 Oxide thicknesses versus time for ring shaped samples, isolated by ceramic rings. Oxidation tests were performed at $500^{\circ} \mathrm{C}, 25 \mathrm{MPa}$.

properties, the wall thickness of an in-pile device made of Titanium could be smaller. The average oxide thickness for Ti grade 2 after 1630 hours of exposition was about $3 \mathrm{~mm}$ (from 17 data points).

\section{Conclusions}

Corrosion of structural and cladding material in the planned Generation IV. Supercritical Water Cooled Reactors can cause at least two problems. First, the corrosion itself can decrease the mechanical stability of the materials and second, the dissolved corrosion products can cause problems in the loop. Therefore, it is crucial to find materials with not only good behavior concerning neutron physics, but also with very good corrosion resistance. It should not be forgotten, that while in other equipment using supercritical water the corrosion can also cause problems, but corroded parts can be relative easily replaced; while in a nuclear reactor, fast and simple replacement of corroded parts in the core is not an alternative. This is the reason, why in this case, proper corrosion resistance is more crucial.

Corrosion tests were designed and performed in a supercritical pressure autoclave in order to get data for the design of an in-pile high temperature and high-pressure corrosion loop. The tests run in two series with four types of materials, in addition the heated test section of the autoclave was also analyzed after the test cycles. The resulted oxidation rates are not limiting the use of the materials from the mechanical strength point of view, but in case of intense oxidation the falling oxides could contaminate the coolant.

\section{Acknowledgement}

This work has been partially supported by VKSZ_14-12015-0021 Hungarian project of the National Research, Development and Innovation Fund. 


\section{References}

[1] Dobashi, K., Kimura, A., Oka, Y., Koshizuka, S. "Conceptual design of a high temperature power reactor cooled and moderated by supercritical light water", Annals of Nuclear Energy, 25(8), pp. 487-505, 1998.

https://doi.org/10.1016/S0306-4549(97)00079-0

[2] Allen, T., Chen Y, Tan, L., Ren, X., Sridharan, K, Ukai, S. "Corrosion of Candidate Materials for Supercritical Water-Cooled Reactors", In: $12^{\text {th }}$ International Conference on Environmental Degradation of Materials in Nuclear Power System-Water Reactors, Salt Lake City, Utah, USA, 2005, pp. 1397-1408.

[3] Nakazono, Y., Iwai, T., Abe, H. "General corrosion properties of modified PNC1520 austenitic stainless steel in supercritical water as a fuel cladding candidate material for supercritical water reactor", Journal of Physics: Conference Series, 215(1), article ID: 012094, 2010.

https://doi.org/10.1088/1742-6596/215/1/012094

[4] Guzonas, D., Novotny, R., Penttilä, S., Toivonen, A., Zheng, W. (eds.) "Materials and Water Chemistry for Supercritical WaterCooled Reactors", Woodhead Publishing, Cambridge, MA, USA, 2018.

https://doi.org/10.1016/B978-0-08-102049-4.09001-2

[5] Glasstone, S., Sesonske, A. "Nuclear Reactor Engineering: Reactor Design Basics", 4th ed., Chapman and Hall, New York, NY, USA, 1994.

[6] Xu, L., Kumar, P., Buldyrev, S. V., Chen, S.-H., Poole, P. H., Sciortino, F., Stanley, H. E. "Relation between the Widom line and dynamic crossover in systems with a liquid-liquid phase transition", Proceedings of the National Academy of Sciences of the United States of America (PNAS), 102(46), pp. 16558-16562, 2005. https://doi.org/10.1073/pnas.0507870102

[7] Imre, A. R., Deiters, U. K., Kraska, T., Tiselj, I. "The pseudocritical regions for supercritical water", Nuclear Engineering and Design, 252, pp. 179-183, 2012.

https://doi.org/10.1016/j.nucengdes.2012.07.007

[8] Imre, A. R., Tiselj, I. "Reduction of fluid property errors of various thermohydraulic codes for supercritical water systems", Kerntechnik, 77(1), pp 18-24, 2012.
[9] Kritzer, P. "Corrosion in high-temperature and supercritical water and aqueous solutions: a review", The Journal of Supercritical Fluids, 29(1-2), pp. 1-29, 2004.

https://doi.org/10.1016/S0896-8446(03)00031-7

[10] Martynova, O. I. "Solubility of inorganic compounds in subcritical and supercritical water", In: Jones, D. G., Slater, J. E., Staehle, R. W. (eds.) High Temperature High Pressure Electrochemistry in Aqueous Solutions, International Corrosion Conference Series, NACE-4, 1st ed., National Association of Corrosion Engineers (NACE), Houston, TX, USA, 1976, pp. 131-138.

[11] Imre, A. R., Házi, G., Horváth, Á., Maráczy, C., Mazur, V., Artemenko, S. "The effect of low-concentration inorganic materials on the behaviour of supercritical water", Nuclear Engineering and Design, 241(1), pp. 296-300, 2011. https://doi.org/10.1016/j.nucengdes.2010.11.011

[12] Horváth, Á., Jákli, G., Horváth, M., Csordás, A., Sikó, L., Imre, A. R. "Study of corrosion in supercritical water", In: Proceeding of the $4^{\text {th }}$ International Symposium on Supercritical Water-Cooled Reactors, Paper No. 57(CD), 2009.

[13] Motta, A. T., Yilmazbayhan, A., da Silva, M. J. G., Comstock, R. J., Was, G. S., Busby, J. T., Gartner, E., Peng, Q., Jeong, Y. H., Park, J. Y. "Zirconium alloys for supercritical water reactor applications: Challenges and possibilities", Journal of Nuclear Materials, 371(1-3), pp. 61-75, 2007. https://doi.org/10.1016/j.jnucmat.2007.05.022

[14] Penttilä, S., Toivonen, A., Rissanen, L., Heikinheimo, L. "GenIV Material Issues - Case SCWR", Journal of Disaster Research, 5(4), pp. $469-478,2010$. https://doi.org/10.20965/jdr.2010.p0469

[15] Ruzickova, M., Hajek, P., Smida, S., Vsolak, R., Petr, J., Kysela, J. "Supercritical water loop design for corrosion and water chemistry tests under irradiation", Nuclear Engineering and Technology, 40(2), pp. 127-132, 2008, https://doi.org/10.5516/NET.2008.40.2.127 